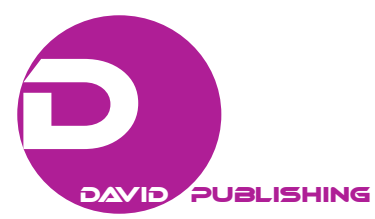

\title{
Significant Learning Experiences of Estonian Basic School Students at a School With the Reputation of a "Happy School”
}

\author{
Tiiu Kuurme, Eda Heinla \\ Tallinn University, Tallinn, Estonia
}

\begin{abstract}
The goal of our study was to find out which school experiences are considered meaningful by 7th and 8th graders in basic schools, which have a reputation as being "happy schools.” The research method used was an open-ended questionnaire to students which focused on their learning experiences, and as background knowledge, observing lessons and interviews with student focus groups. A total of 139 students participated in the study, Grades 7 and 8; 73 boys and 66 girls; and aged 13-15 years. The findings of the learning experiences that students found meaningful and important were school subjects, self-appropriate skills, general knowledge, and skills necessary for life. Three sub-themes emerged in students' learning experiences related to their personal development: social skills, self-related skills, and mental skills. The overwhelming majority of students found that their school is generally a good place to learn important things. Two thirds of students deemed their school a good place, while negative aspects were mentioned by one third of students. That the school is completely bad was expressed by 12 students. We conclude that, for students, significant learning experience is primarily related to learning a variety of subjects and general knowledge necessary for life. At the same time, the acquisition of self-appropriate skills is also considered important. In contrast with students' general perception of heavy study loads, boredom, bullying, and other negative experiences, the students expressed a warm and positive attitude towards their school.
\end{abstract}

Keywords: learning experience, student well-being, school culture and school atmosphere

\section{Description of the Current Situation of General Education in Estonia}

Estonian public media has increasingly been addressing problems, such as lack of the communication skills of youngsters, addiction to smart devices, problems with acknowledging feelings, and the increasing risk of mental health problems. A pilot study by the Estonian Ministry of Education regarding school satisfaction of basic school students which was conducted in 2017 found that the satisfaction rate of 8th graders was 3.2 on a 5-point scale (Valk, 2018). The same low rate was also given to "school happiness." Kuurme (2016) compared the school experiences of 649 students both boys and girls from 10 schools and concluded that there is a substantial correlation between students' satisfaction with school and relations with their peers.

According to a Programme for International Student Assessment (PISA) study conducted in 2018 (PISA, 2019), Estonian students were among the best in the world in their knowledge of subjects, but at the same time, it was found that they feel less relatedness (i.e., a sense of belonging) towards their school and less supported by teachers, place a lower value on collaboration with their co-students, and have a greater experience of

Tiiu Kuurme, Ph.D., associate professor, School of Educational Sciences, Tallinn University.

Eda Heinla, Ph.D., associate professor, School of Natural Sciences and Health, Tallinn University. 
bullying in school than the average in the Organisation for Economic Co-operation and Development (OECD) countries. School is a place where students engage in social relations. Only one third of the girls and $17 \%$ of the boys regarded school knowledge as important. Students lack vision and ideas on how to make their school a better place. Their ideas are bound by existing routines since they have not had a chance to experience that they can have an impact on the school's daily reality (Kuurme, 2016).

In recent years, a paradigm shift has taken place in the Estonian school system, which draws in its main tenets from the constructivist approach to knowledge and the tradition of the progressive education movement. The new paradigm at the institutional level emphasizes student activity, collaborative learning, formative assessment, curriculum integration, and an increased decision-making power of students. Moreover, learning-to-learn skills, collaboration skills, self-efficacy, and subjective well-being are valued. According to the official agenda, learning should become more multifaceted, flexible, and personalized. Despite this, the readiness of schools to adopt these changes varies greatly. Even today, problems, such as authoritarianism, overemphasis on grades, curriculum overload, as well as exhaustion of teachers and students can be encountered in the Estonian school culture. At the same time, there are large differences among schools, and increasingly schools have been able to integrate the abovementioned principles into their daily culture. A strong neoliberal focus on competition somewhat deepens the estrangement: Students are performance-oriented and learn for somebody else. Knowledge obtained in this way may not be integrated into the "true self" of the young people and can be rather restrictive instead of opening the gates to understanding the world.

\section{Theoretical Framework}

About learning. In texts that have now become definitive works on the subject, learning is understood as a socio-cultural activity that is transformed into experiences and individual interpretations of experiences (Säljö, 2003; Jarvis, 2009/2010). From a humanistic perspective (Harish, 2016; Jacobs, 2015; Illeris, 2007; Jarvis 2009/2010), learning is a holistic phenomenon that has been interpreted as a comprehensive process covering the whole of human existence. Education that is aimed at comprehensive personal development is not limited to the transfer of knowledge, but instead activates the entire spectrum of the potential of the intellect to help students confront insecurities and create new opportunities, as well as to lead young people to truth, self-development, and self-awareness. The predominance of memory-oriented fact-based education leaves independent thinking to play a secondary role, drawing mental energy away from higher processes of understanding. A holistic approach covers all dimensions of learning: understanding, meaning, breadth of knowledge, and cultural and social factors. From the perspective of holistic education, the learning experience is life itself as experienced through all of the senses, feelings, and emotions. This perspective highlights concepts, such as contexts, situations, experience, identity, meaning, reflection, and other dimensions of internal life (Harish, 2016; Jacobs, 2015; Illeris, 2007; Jarvis, 2009/2010).

Learning begins with experience and always takes place in a social situation, containing a large amount of so-called “tacit knowledge” (Säljö, 2003; Jarvis, 2009/2010). According to Goffman (2012), human life is characterized by considerable sensitivity to the conditions and assumptions surrounding a situation. Every situation has a social framework and the related experience appears in a physical, social, cultural, intellectual, and psychological context. Thus, learning is contextual, spatio-temporal, and situational. In today's world, where knowledge is accumulated at a fast pace, it is also important to understand how we observe, reflect, perceive, understand, and interpret reality. A learning environment that fosters boldness, trust, and 
self-responsibility forms creative, empathetic, and self-aware individuals who are able to adapt to new situations and solve problems (Illeris, 2007; Harish, 2016; Jacobs, 2015). Illeris (2007) highlighted that the identity-shaping role of learning has increased exponentially in the context of cultural liberalization. For today's young people, it is also important to be able to navigate their inner life, so as not to waste their life on the wrong things. Thus, learning must be organized in a way that links academic qualifications to personality traits as well as the ability to understand both oneself and others.

Liimets (2005) noted that every human activity is tied to the process of giving it personal meaning. Meaning is born through the mutual dynamics of different cultures and people. As an expression of spiritual attitudes molded by a culture, how we instill meaning also indicates how we relate to the world and perceive ourselves. Thus, Liimets defined learning as the creation of the self in a culture and as the creation of culture in the self.

Students' learning situations and experiences are largely shaped in school, which makes school as a context one of the central factors in the process of giving meaning to what is learned. There has been considerable criticism of traditional school education, where the student is in a passive role, the environment is artificial and full of routine, and learning is formal, consumption-oriented, and instrumentalized. School as a context can be a place that produces distress and suffering: devoid of emotion, archaic, personality-stifling, etc. (Säljö, 2003; Youdell, 2011; Simola, 2015). The current dominance of an achievement-oriented mentality can lead to an alienation from learning, whereby it is impossible to say what achievement actually is, as it may be experienced as a sanction or a coercive measure of existence (Liimets, 2005).

Students' inability to control and express their feelings has become another problem: The prevalence of depression and self-destructive lifestyles has increased (Salminen, 2012). There has been a great deal of discussion about the difficulties of changing the school system, as it is a longstanding context with firmly rooted routines and interaction models that have been formed through historical tradition, and it is often seen as the sole possibility (Säljö, 2003). Through its structural factors, the school system also seems to have prescribed a concept of learning that is far from holistic. That is to say, in the acquisition of knowledge, or learning, the content is the transfer of specific units, facts, values, and principles.

This raises the question of how students themselves reflect on school education and what they have learned in school, as well as to what extent they gain additional knowledge (and what kind) about their own abilities and qualities from the experience. "What makes learning meaningful?” could be seen as one of the central questions and answering it one of the central pedagogical pursuits for understanding learning from the perspective of holistic learning. Have-and to what extent- the recent rapid changes also shaken those aspects of the school system that have thus far been taken for granted, as well as the relationship between students and learning, which is generally acknowledged as instrumentalized?

Fink (2003) defined a significant learning experience as one that engages students, makes them enthusiastic about the subject, promotes long-term learning, and helps students see the value of material in the world around them. To Fink, significant learning experiences are situated at the intersection of six categories of learning: Foundational knowledge is the basic knowledge of course-specific information and ideas; learning how to learn emerges whenever students learn new skills that help them become better learners; integration refers to the ability to make connections between specific or universal ideas; caring about others, issues, or concepts is accompanied by change in feelings, interests, or values; and the human dimension is the name given to the category that encompasses the students learning something new about themselves or others. To successfully incorporate all six categories, significant learning experiences have to be designed into the course. 
In other words, the course itself needs to be a significant learning experience. Fink (2003) stated that any time one of these areas of learning is improved, the student's ability to improve in every other area is enhanced. The authors believe that an integrated course, in which learning goals, teaching and learning activities, along with feedback and assessment, are aligned, is the best approach to creating a significant learning experience.

\section{School Culture and School Climate}

A broad exploration of learning through the lens of humanism has led to the conclusion that the learning environment is composed of the school as a whole, including its culture and atmosphere. What makes a school good? What is important in a school?

While the culture of a school is the combination of its values, perceptions, and beliefs, the climate of a school is a reflection of the above in the consciousness of the people of the school (van Houtte, 2005). As a unifier of the society of a school, school culture is rather the embodiment of a cognitive aspect: It is a set of underlying assumptions, views, shared beliefs, opinions, and values. It is supplemented by symbols, myths, rituals, and ceremonies, which, when combined, form the basis for a school as a social system. MacNeil and Maclin (2005) argued that a strong school culture is also a powerful socializer and that it is the duty of school leaders to create a value base that connects all parties. Schools with a strong professional community are better able to provide authentic pedagogy and are more effective at enabling students to succeed. In a successful school culture, the focus is on a school climate that promotes community spirit, as well as mutual understanding and cohesion between all parties.

The school climate comprises several dimensions, such as safety, teaching and learning, social relationships, and environmental-structural factors (Cohen, Mccabe, Michelli, \& Pickeral, 2009). The National School Climate Center defines the school climate in the following ways: "School climate is based on patterns of people's experiences of school life and reflects norms, goals, values, interpersonal relationships, teaching and learning practices, and organizational structures. A sustainable and positive school climate fosters the development and learning necessary for a productive, contributive, and satisfying life in a democratic society. This climate includes norms, values, and expectations that support people in feeling socially, emotionally, and physically safe. People are engaged and respected, students, families, and educators work together to develop, live, and contribute to a shared school vision." Studies have found that a positive school climate helps to solve many problems: It reduces absenteeism, drop-out rates and bullying, boosts academic achievement and motivation, and contributes to building good relationships (King \& Data, 2017; Borkar, 2016).

However, when existing in a group becomes a social pressure and determines what is right or wrong, it results in conformity and the adoption of a specific school "habitus," which is characterized by an obedience to authority, stereotypes, self-denial, and in the worst case, the loss of an authentic identity. In this way, the value environment of a school has a significant impact on what one learns at the school and what kind of citizen they become.

According to van Houtte (2005) and MacNeil, Prater, and Busch (2009), if students' learning experiences are considered important, any changes should start with the school culture. Schools contain different subcultures, and whether the parties (teachers and students in this case) are in opposition, fragmenting, or integrating is an important issue. Schools with a positive and professional culture improve student performance. This motivates teachers, who, in turn, when highly motivated, further boost students' learning outcomes (MacNeil et al., 2009). 


\section{Student Well-Being}

The attractiveness of a school and the enjoyment of attending school are mostly described through subjective well-being. Well-being is defined as a state of successful performance that combines physical, cognitive, and socio-emotional functions throughout a person's life and is expressed in actions valued in a person's cultural environment, satisfactory social relationships, and the ability to overcome moderate psychosocial and environmental problems (Davidson, Rosenberg, \& Moore, 2003).

The precursor to pedagogical well-being has to some extent been the concept of pedagogical love, which recognizes the human dignity of every individual, evokes an authentic experience of the self, promotes independent thinking, and encourages students to recognize their value regardless of performance, appearance, or medical disorders (Skinnari, 2004). Well-being is impossible if the learner is seen as a means of producing learning outcomes and as a performer who is judged on the basis of externally established standards (Skinnari, 2004).

In the humanistic view of learning, pedagogical well-being has become a goal in itself as a quality of the atmosphere of a school. It enables students to focus on learning by allowing energy that would otherwise be spent on coping with pressures, depression, and poor relationships, to be transformed into self-development through learning. From a humanistic perspective, education and teaching should enable a learner to feel that their life is meaningful.

Seligman and Csikszentmihalyi (2000), the founders of positive psychology, distinguish among experiences that are simply pleasant and those that offer higher levels of satisfaction. While pleasantness is limited to the meeting of simpler needs, development-oriented satisfaction creates a positive feeling through experiences where one pushes past his/her previous limits, achieves something greater, and experiences personal growth. Well-being is pedagogically relevant where it improves the prospects of the student.

Pyhalto, Soini, and Pietarinen (2010) and Pietarinen, Soini, and Pyhalto (2014) used the term "pedagogical well-being”-Pupils perceive themselves as active subjects belonging to the school community. The authors' study proves that pupils' pedagogical well-being is primarily regulated by the quality of interaction with peers, teachers, and the school community as perceived by the pupils. At the same time, pupils rarely reported encounters with teachers to be a source of empowerment and emotional support for them. Students' cognitive engagement is highly dependent on the quality of interaction manifested in the daily pedagogical practices adopted in schools. This implies that emotional or cognitive engagements are not individual attributes, but rather, are socially constructed and re-constructed in everyday school interactions. School social environments not only provide challenges. They also have the resources for facilitating students' empowerment, satisfaction and drive to study.

Well-being is defined by Deci and Ryan (2000) for members of the school as a learning process that subjectively promotes relatedness, competence, and autonomy. Relatedness means the students' connection to the school, their fellow students, and teachers. Competence means the students' sense of being able to apply and develop their abilities at school. Autonomy means the students' sense of being able to control what goes on at school and of having sufficient freedom of action and choice.

According to Graham, Powell, and Truscott (2016), the key components of students' subjective well-being are relatedness to the community of their school, good relationships at school on multiple levels, and the values represented in the school culture. Relationships play a critical role in well-being, as they provide an 
experience of whether one is cared about, respected, and valued by others. Relationships create the capacity to feel involved and responsible for one's own learning.

King and Datu (2017) have studied the nature of well-being as a so-called "social contagion": They argue that student well-being is social rather than individual, as it is transmitted in a network of peers to an even greater degree than cognitive vulnerability.

\section{Quality of School Life and Enjoyment of Attending School}

Self-determination theory suggests that students' satisfaction with school is related to the need for autonomy, connection, and self-efficacy (Tian, Chen, \& Huebner, 2014). Finnish researchers, Yoon and Järvinen (2016) have used the term "quality of school life," as students' general perception of their school well-being and satisfaction with their positive and negative experiences of ordinary school life. The aspects of quality of school life are follows: (a) general satisfaction (sense of belonging, happiness at school, and satisfaction with school life); (b) peer relations (making friends, closeness with peers, feelings of alienation, or loneliness); and (c) teacher-student relations (academic and emotional support from teachers, attentive listening to students, friendliness between teachers and students, and treating students fairly). In their study, the authors compared Finnish and Korean students' general satisfaction, peer-relations, and teacher-student relations using the data from the PISA 2012 Test. The analyses showed that Finnish adolescents' general satisfaction with school is more positive than Korean adolescents'.

Lopez-Perez and Fernandez-Castilla (2018) have studied Spanish students' conceptualizations of happiness at school and its link with self-reported happiness and academic achievement. The results showed that, for adolescents, four conceptualizations (“being with friends," "being praised,” "helping,” and "having leisure time") were significant predictors of self-reports of happiness, which at the same time was related to academic achievement. Happiness as "helping" was significantly more frequently mentioned by adolescents than children. The authors conclude that happiness encourages adolescents to perform better and better performance makes them happier. At the same time, grades may have a repercussion on children's well-being. Thus, schools need to ensure that when providing grades they offer positive information-based feedback.

A school satisfaction survey conducted among Estonian students in 2018 (Üldhariduskoolide, 2018) showed that satisfaction with school is highest among fourth grade students. By the end of basic school, satisfaction drops, and then rises again slightly among eleventh grade students. With regard to specific aspects of satisfaction, students are critical of the lack of mobility opportunities at school, the lack of practical application of the acquired knowledge, and collaborative teaching.

Rumma (2017) has defined the enjoyment of attending school among Estonian students through three aspects: students' attachment to the school (i.e., subjective relatedness to the school and beliefs about their school); sense of belonging (i.e., social relatedness to the school, getting on with fellow students and teachers); and engagement with schoolwork (i.e., a positive attitude towards schoolwork, sensing that the schoolwork is meaningful and that time flies when one is learning). According to the research conducted by the authors, the major factors influencing the enjoyment of attending school among Estonian students are: (a) the perceived innovativeness of the school; (b) the significance of the schoolwork, i.e., the work is meaningful and not rote learning; and (c) teachers' student-centered approach to teaching. The more the students perceive that lessons are taught in a student-centered manner and the teacher is approachable, the more they enjoy attending school. Students are happy to study in an innovative school where learning is meaningful and the approach is 
student-centered. Thus, positive emotions at school are primarily tied to the organization of school life.

In summary, the meaning attributed to learning by students is influenced by the socio-cultural context of the school as a whole, perceived well-being, a sense of belonging, relationships at school, the status of the students, as well as the desire to apply oneself.

\section{Objectives}

The goal of our study was to find out which school experiences are considered meaningful by 7th and 8th graders in the basic schools which have a reputation of being "happy" schools.

\section{Specific Objectives}

1. What characterizes learning experiences which students consider meaningful?

2. How do students perceive the influence of learning experiences on their personality development?

3. How is the role of the school and the school culture reflected in the student learning experiences?

\section{Method}

\section{Subjects}

Since 2014, the Estonian Non-Governmental Organization (NGO) "Creative Education" has in-cooperation with the Educational Innovation Centre at Tallinn University—been organizing workshops for teachers on creativity and child-centered methods. Four schools have been collaborating with this NGO for several years. Their reputation indicates that positive changes towards the desired direction have taken place within the culture of these schools. For convenience, we will call these schools A, B, C, and D. A total of 139 students participated in the study, Grades 7 and 8; 73 boys and 66 girls; and aged 13-15 years.

School A ( $N=26,13$ girls and 13 boys) is a 9-year basic school with a private school status which was modeled after the Danish free school concept, it has 141 students. The school identifies itself as a community school where parents have major co-decision power. School B ( $N=35,18$ girls and 17 boys) is a municipal school in a large suburb of Tallinn primarily consisting of private houses. The school has around 800 students. Students attending this school come from the middle class. School C ( $N=56,24$ girls and 32 boys) is well known for its active and experiential teaching methods and is located in a former large industrial town which is now half deserted. It is a full-cycle 1-12 grade comprehensive school with 352 students: Both Estonian- and Russian-speaking children attend this school. The school has many children who have a problematic social background. School D ( $N=22,11$ girls and 11 boys) is a Waldorf school with a private school status in a smaller village which, together with the kindergarten, has a little over 100 students. Parents have chosen this school for their children due to its alternative pedagogical approach. Compared to schools B and C, which have modern equipment, the private schools $\mathrm{A}$ and $\mathrm{D}$ are located in old cramped buildings, which have a considerably less attractive physical environment.

\section{Instruments and Data Analysis}

The open-ended student questionnaire, which focused on their learning experiences. As background knowledge we used observing lessons, and interviews with student and teacher focus groups. The responses to the student questionnaire were analyzed using the method of qualitative content analysis and the quantitative method of International Business Machine (IBM) Statistic Package for Social Science Statistics (SPSS) Version 26. The students' interviews were analyzed by the method of qualitative content analysis. 


\section{Results}

\section{Question One: What Characterizes Learning Experiences Which Students Consider Meaningful?}

Here, we analyze open-ended answers to the questions: What do you think you have learned at school is important? Describe some great experiences when you felt you were learning something new? Grouping the answers on the first question the following main categories emerged: school subjects $(N=68 ; 49 \%)$; self-appropriate skills ( $N=51 ; 37 \%$ ): social skills, mental skills, and self-awareness (we analyze the answers in this category by answering the second research question); general knowledge and skills necessary for life ( $N=$ 7; 5\%). Only one student mentioned a grade, which is, in the Estonian education context of generally strong performance orientation, somewhat extraordinary. All of the schools mentioned above have given up on summative assessment in the primary school, yet in Grades 7 and 8 students are also assessed numerically, except in the Waldorf School. Two students replied that they had not learned anything important at school, with the majority feeling it has been insignificant. Five students answered that everything is important, and five could not answer the question. It is worth mentioning that none of the students mentioned that they had learned anything from smart devices.

Boys most often mentioned school subjects (57\% of boys and 39\% of girls); all subjects were listed here.

Students: I find that the things I have learned in mathematics, biology, social studies, Estonian and geography, as well as in English, are all very important, because they develop both my horizons and my thinking. I learned a lot about myself in school. Reading and writing are the most important of these, math is definitely important.

Learning general knowledge and skills necessary for life, such as choosing a career, using money, being aware of the effects of alcohol, and planning time, were equally important for boys and girls (5\%).

Student: I cannot say anything exact, but I have gained a lot of experience, for example, how to cook, how to handle money and things like that. I have learned a lot about what I need in the future, what I need to know for life and also what I think I do not need in life.

Students' answers to the question regarding their greatest learning experiences were divided into the following categories: understanding in school subjects ( $N=67 ; 48 \%)$; school trip: museum, hiking, and camping ( $N=14$; $10 \%)$; school hobby activities $(N=12 ; 9 \%)$; activities outside school $(N=19,14 \%)$, and "I do not know, I cannot remember" $(N=27 ; 19 \%)$. Boys experienced new learning experiences in subjects more often than girls (56\% of boys and 39\% of girls), for example, practical experiments, learning a new topic, personal achievement, and acquiring new skills (programming, woodwork, and physical skills).

Students: For me, it was an interesting experience to prepare for the quiz in chemistry where I participated with two of my classmates. The teacher helped us and taught us new things. After I have fully learned and understood the topic, it feels like I have achieved something big.

Although all schools organized many extracurricular, experiential activities where students were actively involved, they were only remembered in the context of meaningful learning experiences by relatively few students.

Students: All the hikes we have been on have developed me a lot and added to my motivation. In nature camps, I have learned more about nature and being out in nature and learning is interesting. Project days of our school. Creative festival and the school café days. 


\section{Question Two: How do Students Perceive the Influence of Learning Experiences on Their Personality Development?}

Here, we come back to the question: What do you think you have learned at school is important? We look in more detail at students' meaningful learning experiences related to their personal development. Three new categories emerged from the data which could be added: social skills $(N=35 ; 25 \%)$, self-relevant skills $(N=11$; $8 \%)$, and mental skills ( $N=5 ; 4 \%)$.

Reflecting on the gender of the respondents, it is striking that boys are strongly fixed on school subjects and do not mention anything connected to personal development to any extent (all three categories mentioned; $23 \%$ of girls and $14 \%$ of boys). This indicates that girls have a stronger inner connection to school and a tendency to analyze themselves which boys have not yet developed.

Girls considered learning social skills at school to be more important than boys did (35\% of girls and 16\% of boys), for example, communication, friendships, asking for help, cooperation skills, caring for others, etc.

Students: I have learned from school that every person is different, whether in terms of thinking or appearance, etc., and one should never be condemned for that difference. I think everything is important in school, but the most important thing is how to communicate with people. For me, it is important that we get to know each other and get to know others at school.

Respecting differences was emphasized in the school which included both Estonian- and Russian-speaking students. The most diverse list of social skills originates from this school. The answers indicate that students' value peaceful community building and others around them.

Self-relevant skills were more important for girls (11\% of girls and $6 \%$ of boys), for example, diligence, conscientiousness, independence, self-advocacy, self-analysis, self-expression, responsibility, understanding of one's feelings, etc.

Students: I think that in school, in addition to skills, I have learned a lot about independence and overcoming difficulties. Although you should not expect dreams and wishes to come true easily and quickly, before you have to work hard for it. Mental skills were equally important for boys and girls (4\%), for example, problem-solving, independent-thinking, immersion in activities, attention, creative thinking, etc.

Students: I have learned that school is not just about education, but that many subjects simply develop your thinking and creativity.

To clarify the above, we asked a separate question about personal development (we excluded subjects and life skills): What important things you have learned about your personality at school? Here, only $18 \%$ of students said they have learned nothing about themselves at school. Most of the students had learned self-relevant skills ( $N=56$; 40\%): "I get easily irritated, I am lazy, brave, and unique”; social skills ( $N=39$; 28\%): "I can communicate, ask for help, I have learned cooperation skills, taking others into account, caring for others, caring”; and mental skills ( $N=19 ; 14 \%)$ : “I am mentally capable, creative, I can solve problems, I can think independently.”

Boys valued self-relevant skills more (45\% of boys and $35 \%$ of girls).

Students: I am brave and dare to take things that are right but not everyone may like it. I learned that everything I do is sometimes right and sometimes wrong, but from these wrong decisions I have always deduced why it happened.

Girls valued social-skills more (35\% of girls and $22 \%$ of boys).

Students: I am open and cooperative. If you cannot be at school yourself, then in life you will have a hard time finding your identity. At school, I have learned about my personality that I am very friendly and caring towards people, I am 
always ready to cooperate and I do not like to leave my comfort zone very much. I have found out I am pretty noisy but a good friend to many.

Boys and girls valued mental skills equally.

Students: The fact that some things take me longer to understand and that this is normal. I am good at studying. I have learned a lot about what I am strong in and what I have a talent for and where to go next. I have learned about myself that I am a much more creative and curious person.

Of the self-development skills needed for life studied at school, students considered self-relevant skills ( $N$ = 26; $19 \%)$ and then social skills $(N=20 ; 14 \%)$ to be the most important, only a few valued mental skills $(N=2)$.

Students: If you feel tired, you just have to be stronger and move on. Do not give up quickly. And all I do is happy to do it. I have learned at school that "failure" is a part of life and it is perfectly normal. To be honest, the grade that I get may not affect my future life at work or with my family, basic knowledge is there.

\section{Question Three: How is the Role of School and The School Culture Reflected in the Student Experiences?}

We will here analyze the answers to the questions: "Explain how your school is a good (or bad?) place to learn important things!” and "What makes for a meaningful lesson that motivates you to learn?”

The overwhelming majority of students found that their school is rather a good place to learn important things. Two thirds $(N=106)$ of students deemed their school a good place, while negative aspects were mentioned one third of students $(N=52)$. That the school is completely bad was expressed by 12 students (for example, ideas do not work, no help for later life, old-fashioned organization, and weak education). A more detailed positive aspects analysis enabled us to distinguish between the following categories: "my school is generally good" ( $N=35$; 31\% from respondents): "good place to learn, good ideas, interesting projects, innovative methods; and good teachers" ( $N=32 ; 28 \%$ from respondents): "smart, attentive, helpful, demanding enough, explains the substance well”; good teaching and subjects ( $N=22 ; 19 \%$ from respondents): "I can learn important things, I get knowledge, I develop my creativity, useful and interesting subjects; good school atmosphere” ( $N=17 ; 15 \%$ from respondents): students are taken into account, students' well-being is considered, people are friendly, individual differences are taken into account, different abilities.

School was generally considered a good place for $35 \%$ of girls and $27 \%$ of boys.

Students: Bad because it is school. Good thing this is the best school. I think our school is a good opportunity to learn/discover one's personality and consider others. We learn through creation. And I like that. We do not learn for grades, but for ourselves. My school is very good precisely because our personality is not killed or suppressed. I think our school is a very good place to study. Students are allowed to plan their own time, do teamwork, and show their creativity and ingenuity.

Girls valued teachers and their skills more than boys valued teachers (31\% girls and 26\% boys).

Students: There are many young teachers in this school who understand our problems and are looking for a good solution. I think my school is a pretty good place to study, because there are very helpful teachers in this school who can give help lessons if the student does not understand the subject.

Boys and girls rated good teaching methods and necessary subjects equally (19\% of respondents).

Students: My school has very good electives where it is possible to study career studies, economics studies. It gives students a chance to think about their future. There are different ways for teachers to teach the most important things (e.g., to approach creatively and not just to memorize formulas). 
Boys and girls also praised the good school atmosphere almost equally (15\% of respondents).

Students: Here, at school, we focus on collaboration and creativity, and that helps us understand things smarter. Our school hosts many joint and interesting events and projects that make the school exciting and provide a change from regular school lessons. My school is good, because there is a lot of thought here for the well-being of the students and for everyone to be good.

Boys mentioned bad things about their school more often than girls (boys $N=26$ and girls $N=14$, from 139 students). The following categories were here distinguished: school organization ( $N=15$, many lessons, heavy workload, unnecessary subjects, and meaningless events); bad teachers ( $N=15$, lessons are boring, cannot teach, and teacher does not help); and school environment ( $N=10$, bad food, cannot use phone, obligation to wear a school uniform).

Students: School life is too old, you could let go of old school life and move on to new school life. Long hours and school days, food could be better. I do not feel free here. Phones are forbidden, you cannot always dress freely. Teachers are evil and it takes away the mood for learning. My school is bad for learning important things, because young teachers cannot teach.

The students found that a good teacher is the main aspect $(N=50$; 36\%) that makes for a meaningful lesson that motivates them to learn. A good teacher is someone who makes the lesson interesting and is motivated in their job, capable, calm, fun, and a good communicator. As the next most important component, the students listed the use of different teaching methods in class $(N=43,31 \%)$. Teaching methods that were considered interesting by the students included group work, playing games, outdoor learning activities, discussions, the integration of different subjects, and practical tasks. While a good teacher was considered equally important by both boys and girls, girls valued different teaching methods more highly. Only a 10th of the students could not say what makes for a meaningful lesson, of which the majority was boys.

\section{Discussion and Conclusions}

The goal of our study was to find out which school experiences are considered meaningful by 7th and 8th graders in the basic schools which have a reputation for being "happy" schools. The responses given to the open-ended questionnaire by the students from the four schools that participated in the study confirmed that students believe their school to simply be a good place. More precisely, that it is a place with a good atmosphere, where one can learn subjects and acquire general knowledge that are necessary in life, where the teachers are knowledgeable, approachable, and use different teaching methods, and where one can also gain knowledge about oneself. At school, students are typically concerned with restrictions on the use of smart devices, the school uniforms, and excessively long school days. It can be seen that positive evaluations involve more important things, while negative evaluations relate to more superficial factors. Fink's (2003) six categories of meaningful learning: basic knowledge, application, integration, human dimension, caring, and learning to learn, were also reflected in the meaningful learning experiences of the students who participated in our study. Fink (2003) defined a significant learning experience as one that engages students, makes them enthusiastically about the subject, promotes long-term learning, and helps students see the value of material in the world around them. Fink's taxonomy has also been used and studied in practice (Levine, Fallahi, Nicoll-Senft, Tessier, Watson, \& Wood, 2008) and it has been found that four dimensions worked effectively in college settings: human dimension, learning how to learn, foundational knowledge, application. It follows that a 
school culture that values a humane approach to learning and the well-being of all parties in the school may be a prerequisite for Fink's categories of meaningful learning.

More specifically, the learning experiences that students find meaningful and important were, in particular, school subjects, then self-appropriate skills (social skills, mental skills, and self-awareness), followed by general knowledge and skills necessary for life. Only one student mentioned a grade, which is, in the Estonian education context of generally strong performance orientation, somewhat extraordinary. School subjects were listed most frequently among important learning experiences. In a study of personal development interviews conducted at a secondary school in Hamburg (Häbig, 2018), students similarly mentioned academic performance most often instead of self-management and the broader objectives of learning that the researchers hoped to see in the responses. It can be concluded that students' understanding of learning can indeed be narrow, and is often limited to school subjects. Accordingly, there is a need to guide students to understand learning more broadly as a process aimed at themselves as a person, i.e., to understand learning as the development of mental, personal, and social skills.

Three sub-themes emerged in students' learning experiences related to their personal development: social skills, self-related skills, and mental skills. We asked students separately about their personal development: "What important things have you learned about your personality at school?” Here, only one fifth of the students answered that they had not learned anything about themselves at school. In their school, the students valued education that is not only limited to factual knowledge, but also awakens their full potential, supports self-development and self-awareness, and helps to navigate their inner life and confront insecurities: A learning environment that fosters boldness, trust, and self-responsibility forms creative and self-aware individuals who are able to adapt to new situations and successfully solve problems in various situations (Illeris, 2007; Harish, 2016; Jacobs, 2015). The way students described their social and self-regulatory skills indicates a strong link to ethics and values as well as strong connection between developing selfhood and learning. By extrapolating the results to all schools, it can be said that students expect learning activities that ensure a good academic level while also developing their personality and understanding of themselves and others, as well as supporting personal identity.

To answer the question "How is the role of the school and the school culture reflected in the students' learning experiences?” we analyzed the question: Explain how your school is a good (or bad?) place to learn important things! The overwhelming majority of students found that their school is rather a good place to learn important things. Two thirds of students deemed their school a good place, while negative aspects were mentioned by one third of students. That the school is completely bad was expressed by 12 students. A more detailed analysis of the positive aspects allowed us to distinguish the following categories: "My school is generally good" (good ideas, interesting projects, and innovative methods); "We have good teachers" (smart, attentive, helpful, and demanding enough); "We have good teaching methods and learning subjects" (gaining knowledge, and I develop creativity); and "Our school has a good atmosphere" (taking into account students, students' well-being, and individual differences). The attractiveness of a school and the enjoyment of attending school are mostly described through the subjective well-being of students and teachers. According to Graham et al. (2016), the key components of students' subjective well-being are relatedness to the community of their school, good relationships at school on multiple levels, and agreement with the values of the school culture. Based on Deci and Ryan (2000), subjective well-being for members of the school derives from a learning 
process that promotes relatedness, competence, and autonomy. Of these, the students who participated in our study perceived competence the most: "Our school has interesting projects, innovative methods; we have good teaching methods and subjects, electives are useful and interesting, and we are able to develop our creativity." Thus, the students were satisfied with being able to apply and develop their abilities at school. Development-oriented satisfaction, in turn, creates a positive feeling through pushing past one's previous limits and experiencing personal growth. Second, in frequency was that the students perceived relatedness to their school, fellow students, and teachers: That other people are friendly, individual differences are taken into account; teachers are attentive, helpful, and happy to communicate with students. Third, in frequency was that the students perceived autonomy; being able to control what goes on at school and having sufficient freedom of action and choice: "Our proposals are heard, we are free to choose our electives, we can suggest innovative teaching methods and activities, and our well-being is considered.”

Additionally, there was evidence of the students understanding that they too are responsible for maintaining good relationships in school. Teachers' kindness, attentiveness, understanding, and good teaching abilities were highlighted. This can partly be attributed to the fact that, according to research conducted in Estonia, a quarter of both primary and secondary school students suffer from depression and the risk of depression, while a third of primary school students suffer from behavioral disorders and nearly a quarter from anxiety disorders (Vaimsetervise, 2020). Children need adults that offer them security, peace, and recognition — everything discussed in theories on well-being.

Based on Rumma (2017), enjoyment of attending school was noted in the learning experiences of the students from the four so-called "happy schools" as follows:

1. The students affirmed that the management, teachers, and students of their school are open to innovation;

2. The students valued learning that is necessary for life and acquiring self-related skills;

3. The students valued teachers highly, because they are knowledgeable, attentive, helpful, sufficiently demanding, and able to explain their subject well.

\section{References}

Borkar, V. N. (2016). Positive school climate and positive education: Impact on students' well-being. Indian Journal of Health and Wellbeing, 7(8), 861-862.

Cohen, J., Mccabe, E. M., Michelli, N. M., \& Pickeral, T. (2009). School climate: Research, policy, practice, and teacher education. Teacher's College Record, 111, 180-213.

Davidson, L., Rosenberg, M. L., \& Moore, K. A. (2003). Well-being and the future: Using science knowledge to inform practice and policy. In M. H. Bronstein, L. Davidson, C. L. M. Keyes, and K. A. Moore (Eds.), Well-being: Positive development across the life course (pp. 525-542). Mahwah, NJ and London: Lawrence Erlbaum Associates Publishers.

Deci, E. L., \& Ryan, R. M. (2000). The "what” and "why” of goal pursuits: Human needs and the self-determination of behavior. Psychological Inquiry, 11(4), 227-268.

Fink, L. D. (2003). Creating significant learning experiences: An integrated approach to designing college courses. San Francisco, CA: Jossey-Bass.

Goffman, E. (2012). Vuorovaikutuks en sosiologia (Sociology of interaction). Tampere: Vastapaino.

Graham, A., Powell, M. A., \& Truscott, J. (2016). Facilitating student well-being: Relationships do matter. Educational Research, 58, 366-383.

Häbig, J. (2018). Eine Untersuchung von Lernentwicklungsgesprächenzwischen Lernenden, Lehrpersonen und Elternausschulentwicklungsteoretscher Perspektive (An investigation of learning development conversations between learners, teachers and parents from development theoretical perspective). In E. Z. M. Strauss, \& N. C. Häbig, J. (Eds.), Dimensionen von Schulentwicklung. Verständnis, Veränderung und Vielfalteines Phänomens (pp. 169-186). Münster: 
Waxmann Verlag.

Harish, J. (2016). Mind, thinking and creativity. Cadmus, 2(6), 118-127.

Illeris, K. (2007). How we learn? Learning and non-learning in school and beyond. London and New York: Routledge.

Jacobs, C. (2015). Overcoming the educational time warp: Anticipating a different future. Cadmus, 2(5), 1-15.

Jarvis, P. (Ed.). (2009/2010). Learning to be a person in society: Contemporary theories of learning. KnudIlleris. London and New York: Routledge.

King, R. B., \& Datu, J. A. (2017). Happy classes make happy students: Classmates’ well-being. Journal of School Psychology, 65, 116-128.

Kuurme, T. (2016). Tüdrukud ja poisidkoolist ja enesestkoolis (Girls and boys about school and about themselves at school). In Sugu ja hariduskeeles ja meeles (lk. 121-173). Tallinn: Eesti Naisühenduste Ümarlaua Sihtasutus. Retrieved from http://www.haridusjasugu.ee/wp-content/uploads/Tydrukud_ja_poisid_koolist_ja_enesest_koolis.pdf

Levine, L. E., Fallahi, C. R., Nicoll-Senft, J. M., Tessier, J. T., Watson, C. L., \& Wood, R. M. (2008). Creating significant learning experiences across disciplines. College Teaching: Heldref Publications.

Liimets, A. (2005). Bestimmung des lernenden Menschen auf demWegeder Reflexionüber den Lernstil (Determination of the learner through reflection on the learning style). Frankfurt am Main, Berlin, Bern, Bruxelles, New York, Oxford, Wien: Peter Lang Verlag.

Lopez-Perez, B., \& Fernandez-Castilla, B. (2018). Children's and adolescents' conceptions of happiness at school and its relation with their own happiness and their academic performance. Journal of Happiness Studies, 19, 1811-1830.

MacNeil, A., \& Maclin, V. (2005). Building a learning community: The culture and climate of schools. Retrieved from https://cnx.org/contents/Q8VzQ7y3@2/Building-a-Learning-Community-The-Culture-and-Climate-of-Schools

MacNeil, A., Prater, D. L., \& Busch, S. (2009). The effects of school culture and climate on student achievement. International Journal of Leadership in Education Theory and Practice, 12(1), 73-84.

National School Climate Center. (n.d.). Retrieved from https://www.schoolclimate.org/school-climate

Pietarinen, J., Soini, T., \& Pyhalto, K. (2014). Students' emotional and cognitive engagement as the determinants of well-being and achievement in school. International Journal of Educational Research, 67, 40-51.

PISA 2018. (2019). Eestitu lemused (Estonian results). SA Innove. Retrieved from https://www.innove.ee/uuringud/pisa-uuring/kirjandus

Pyhalto, K., Soini, T., \& Pietarinen, J. (2010). Pupils’ pedagogical well-being in comprehensive school—Significant positive and negative school experiences of Finnish ninth graders. European Journal of Psychology of Education, 25, $207-221$.

Rumma, K. (2017). Projekt “Õpikäsituseprofiil” Uuringutulemusteraport (Project “Learning Concept Profile” Report of research results). Haridus- ja teadusministeerium, Tallinna Ülikool. Retrieved from https://www.hm.ee/sites/default/files/okprofiil_rumma.pdf

Säljö, R. (2003). Õppiminetegelikkuses: Sotsiokultuuriline käsitlus (Learning in practice: Socio-cultural approach). Tartu: Eesti Vabaharidusliit.

Salminen, J. (2012). Koulunpirulliseet dilemma (The diabolical dilemma of school). Helsinki: Kusstannusosakeyhtiö OY.

Seligman, M., \& Csikszentmihalyi, M. (2000). Positive psychology. American Psychologist, 55(1), 5-14.

Simola, H. (2015). Koulutusihmeenparadoksit: Esseitäsuomalaisestakoulutuspolitiikasta (The paradoxes of the educational miracle: Essays on Finnish education policy). Tampere: Vastapaino.

Skinnari, S. (2004). Pedagoginenrakkaus (Pedagogical love). Juva: WS Bookwell OY.

Tian, L., Chen, H., \& Huebner, E. S. (2014). The longitudinal relationships between basic psychological needs satisfaction at school and school-related subjective well-being in adolescents. Social Indicators Research, 119(1), 353-372.

Üldhariduskoolide (2018). A rahuloluküsitlusetulemused. (2018). (Results of the satisfaction survey of General education schools in 2018). Aruanne. Innove. Retrieved from https://www.innove.ee/wp-content/uploads/2020/01/yldhariduskoolide_rahulolukysitluste_tagasiside_aruanne_2018.pd $\mathrm{f}$

Vaimseterviserohelineraamat. (2020). Green paper on mental health. Tallinn: Sotsiaalministeerium. Retrieved from https://www.google.com/search?q=vaimse+tervise+roheline+raamat\&oq=Vaimse+tervise+rohelin\&aqs=chrome.1.69i5 7j0i19j69i60l2.7280j0j4\&sourceid=chrome\&ie=UTF-8

Valk, A. (2018). Rahulolumõõtmine 2017: Õpilaste ja õpetajateheaoluüle-Eestilisesrahuloluküsitluses, lühiülevaade 2017. a. tulemustest (Measurement of satisfaction in 2017: Well-being of students and teachers in the all-Estonian satisfaction survey, brief overview in 2017. Results). Retrieved from https://www.hm.ee/sites/default/files/rahulolu_2017.pdf 
Van Houtte, M. (2005). Climate or culture? A plea for conceptual clarity in school effectiveness research. School Effectiveness and School Improvement, 16(1), 71-89.

Yoon, J., \& Järvinen, T. (2016). Are model PISA pupils happy at school? Quality of school life of adolescents in Finland and Korea. Comparative Education, 52(4), 427-448.

Youdell, D. (2011). School trouble: Identity, power and politics in education. London and New York: Routledge. 